\title{
Embodiment and the Construction of Social Knowledge: Towards an Integration of Embodiment and Social Representations Theory
}

\section{GLIODHNA O’GONNOR}

\section{ABSTRACT}

Recent developments in the psychological and social sciences have seen a surge of attention to concepts of embodiment. The burgeoning field of embodied cognition, as well as the long-standing tradition of phenomenological philosophy, offer valuable insights for theorising how people come to understand the world around them. However, the implications of human embodiment have been largely neglected by one of the key frameworks for conceptualising the development of social knowledge: Social Representations Theory. This article seeks to spark a dialogue between Social Representations Theory and embodiment research. It outlines the position the body occupies in the existing theoretical and empirical social representations literature, and argues that incorporating concepts gleaned from embodiment research may facilitate a more comprehensive account of the aetiology of social representations. The value of analytic attention to embodiment is illustrated with reference to a recent study of social representations of neuroscience, which suggested that embodied experience can shape the extent to which people engage with certain topics, the conditions under which they do so, and the conceptual and affective content of the ensuing representations. The article argues that expanding Social Representations Theory's methodological and conceptual toolkit, in order to illuminate the interplay between embodied experience and social communication in the development of common-sense knowledge, promises productive directions for empirical and theoretical advancement.

Keywords: Social representations, embodiment, body, phenomenology

\section{INTRODUCTION}

Affirmation of the primacy of the body in human consciousness stretches back to the very beginnings of the discipline of psychology. In a speech originally 
delivered in 1904, William James, often credited as the father of modern psychology, stated:

The world experienced (otherwise called the 'field of consciousness') comes at all times with our body as its center, center of vision, center of action, center of interest (...) The body is the storm center, the origin of coordinates, the constant place of stress in all that experience-train. Everything circles round it, and is felt from its point of view. (James, 1912/2003, p. 89)

As the nascent field of psychology continued to develop through the early- to midtwentieth century, the body retained centrality, forming a foundational touchstone for the successively dominant paradigms of psychoanalysis and behaviourism. This was to change with the 'cognitive revolution' of the 1950s. The cognitive psychology that dominated the remainder of the $20^{\text {th }}$ century constituted the human mind as an information-processing machine that was both decontextualised and disembodied (Danziger, 1990). The body, as well as society, receded from psychological theory. However, theories of embodiment have lately undergone a resurgence, restoring the body to the mainstream of psychological and social theory (Ignatow, 2007; Meier, Schnall, Schwarz, \& Bargh, 2012; Niedenthal, Barsalou, Winkielman, Krauth-Gruber, \& Ric, 2005; Rose, 2013; Schubert \& Semin, 2009; Wilson, 2002). This recent research provides strong evidence for the constitutive influence of the body on the content and process of thought. Nevertheless, these implications of human embodiment have been largely neglected by one of the key frameworks for theorising the development of social knowledge: Social Representations Theory (SRT). This paper draws on phenomenological philosophy and the emerging field of embodied cognition to argue that a fuller picture of the development of social representations requires consideration of the central role that the body plays in forming the conceptual and affective content from which representation is built.

\section{SOCIAL REPRESENTATIONS THEORY}

SRT is a social psychological theory designed to explore the socially shared common-sense knowledge that permeates everyday thought, feeling and behaviour. This common-sense knowledge is operationalised in the concept of 'social representation', which refers to the network of values, ideas and practices that constitute a 'lay theory' about a given topic. Social representations furnish a lens through which people make sense of their world, both as individuals and as communities with shared systems of meaning (Moscovici, 1973). Historically, SRT arose in response to the individualisation of social processes that was perpetuated in the social psychological laboratories of post-war North America (Farr, 1996; Moscovici, 1972). As such, its focus has traditionally been on redirecting the social psychological lens away from the atomised individual and into society. Epistemologically, SRT tends to align with a form of 'weak' social 
constructionism (Searle, 1995). Social representations are conceived as residing across rather than within individual minds, inhabiting the 'between-space' where individual and society connect (Jovchelovitch, 2007).

In locating representation in the interplay between the individual and society, SRT roots cognition firmly in-the-world. That is, meaning does not issue from the operations of a decontextualised mind, but from an individual's engagement with their wider environment. In accordance with its constructivist orientations, SRT has tended to position social communication as the source of the raw material from which social representations are built. Importantly, however, people's engagement with the world around them is not purely social or symbolic: it is also corporeal. Our being-in-the-world is both enabled and mandated by our embodiment as physical organisms whose sensorimotor capacities structure what and how we experience (Crossley, 1995). Jovchelovitch (2007) affirms the significance of embodiment by acknowledging the contribution of Merleau-Ponty to the intellectual traditions on which SRT draws. Yet despite its coherence with the theoretical principles of SRT, the role of embodiment in the genesis of social representations has thus far received little formal elaboration. This paper considers how SRT can be enriched by acknowledging that the 'stuff' of social representation is not purely intellectual or idealistic, but also embodied.

\section{THEORIES OF EMBODIMENT}

The body has a long and turbulent history in western philosophical thought. The beginning of modern philosophy is traditionally sited in Descartes' Cogito, which instigated a fundamental split between mind and body. Descartes (1637/1980) located the essence of the person in a mental plane that was abstract and transcendental, with the body relegated to a subsidiary supporting role. The legacy of Cartesian dualism remained evident throughout $18^{\text {th- }} 19^{\text {th }}$ century philosophical and religious doctrines, and indeed persists today (Johnson, 1987; Ryle, 1949). It was a reaction against these prevailing dualist logics that sparked the emergence of phenomenological philosophy in the $20^{\text {th }}$ century. Merleau-Ponty (1945/2002) rejected the Cartesian decoupling of mind from body, arguing that human consciousness cannot be abstracted from our corporeality. For Merleau-Ponty, the body is not simply an object whose existence can be doubted or affirmed by rational thought (à la Descartes); rather it is the very means of our thinking (Crossley, 2001a). The 'bodily turn' in social theory, which is predicated on Merleau-Ponty's work, contends that knowledge is not purely idealistic or intellectual, but rooted in the sensorimotor experiences through which we acquired it: what we saw, heard, smelled, tasted and touched. Our symbolic capacities are premised on the raw material provided by our sensory faculties, because these features of human embodiment dictate that there are certain ways in which we can (or must) experience the world, and other ways in which we cannot (Johnson, 1987; MacLachlan, 2004). 
Accepting the embodied nature of thought fundamentally challenges the amodal approaches to cognition that have dominated psychology since the cognitive revolution (Pecher \& Zwaan, 2005). It similarly challenges the notion that the appropriate unit of psychological analysis is the atomised, self-contained individual. Embodied experience is always grounded in an external environment (Barsalou, 2008). Merleau-Ponty insisted that embodiment necessarily entails worldliness, to the extent that body and world are elements of a single system (Crossley, 2001a). This is elaborated by Clark and Chalmers' (1998) concept of 'extended cognition', which posits that objects within the environment, which extend action and perception capabilities, can legitimately be conceived as 'part' of mind. Tools, computers and shoes facilitate action that would not otherwise be possible, and in performing that action they are functionally experienced as an extension of one's body (Hirose, 2002; Marsh, Johnston, Richardson, \& Schmidt, 2009). Gibson (1979) coined the term 'affordances' to describe the opportunities that an object offers for an individual; for example a straight ledge might afford sitting, climbing, or relief from a heavy load. Gibson's ecological approach argues that perception of an object involves not only its visual characteristics, but immediate registering of the affordances that object offers for action. Importantly, affordances do not exist either within the individual or within the environment, but in the distinctive and temporally-specific relationship between them (Marsh et al., 2009). Thus, this research tradition suggests that mind does not end at the boundaries of the skull, nor even the skin: mental activity is fundamentally and intrinsically rooted in the body's interaction with the outer world.

More recently, these insights into the nature of embodiment have been complemented and expanded by emerging research in embodied cognition (Meier et al., 2012; Niedenthal et al., 2005). Embodied cognition has yet to develop a coherent theoretical framework, with different researchers defining the concept in different ways (Goldman \& de Vignemont, 2009; Spackman \& Yanchar, 2014; Wilson, 2002). However, one overarching theme of this research paradigm is that sensorimotor experiences selectively evoke particular psychological contents. For example, asking people to hold a pencil between their teeth, thereby simulating the muscular patterns of a smile, elevates their levels of positive affect (Soussignan, 2002). Clenching one's hand into a fist activates concepts relating to power (Schubert, 2004). People report higher levels of agreement with arguments that they hear while nodding their head up and down than while shaking it from side to side (Wells \& Petty, 1980). Such findings indicate that bodily states constitute, rather than merely reflect, the conceptual and affective material that is active in the mind at any particular time.

Research in embodied cognition additionally suggests that embodiment's effects on perception and action are often mediated by widely-circulating linguistic metaphors that encode thoughts or emotions in terms of sensory experiences (Gibbs, 2005; Lakoff \& Johnson, 1980). For example, happiness is often discursively equated with lightness and anger with tightness or heat (Lupton, 
1998). Research has found that placing people in a heated environment increases the availability of anger-related conceptual knowledge, while exposing them to anger-related emotional primes produces higher estimations of the temperature of their environment (Wilkowski, Meier, Robinson, Carter, \& Feltman, 2009). Similarly, drawing on the metaphorical equation of spatial location and affect (e.g. feeling 'up' or 'down'), experimental participants are quicker to evaluate positive words that appear at the top of a screen (Meier \& Robinson, 2004).

These metaphor-based embodiment effects extend into the domain of social relations. For instance, across English-speaking countries, 'warmth' - a descriptor which captures a complex of traits such as friendliness, helpfulness, sincerity and trustworthiness - is the most primary dimension of person perception, with warmth judgements made spontaneously and within fractions of seconds (Fiske, Cuddy, \& Glick, 2007). Warmth is important for intergroup as well as interpersonal relations: warmth judgements are a key dimension of stereotype content, predicting both symbolic and behavioural discrimination. Representations of feminists and Arabs, for example, are often characterised by imputations of interpersonal coldness (Fiske et al., 2007). Embodiment research indicates that encounters with others judged interpersonally warm or cold are paralleled by physical sensations of warmth or coldness: for example, people perceive room temperature to be colder following an experience of social rejection (Zhong \& Leonardelli, 2008). This implies that perceptions of others are physically felt as well as thought. The effects of embodied experience resonate on the level of the social world as well as individual cognition.

The positioning of metaphor as the mediator of embodiment effects is important in offsetting an interpretation of embodied cognition as implying biological determinism of psychosocial content. Although some metaphorical links between psychological and bodily states may have an innate physiological basis (such as the equation of anger with heat, or happiness with smiling), others are elaborated by and vary across particular cultures. These cultural variations are reflected in embodiment research (Cohen \& Leung, 2009). For instance, experimental evidence suggests that adopting a 'head high, chin up' posture triggers greater endorsement of honour beliefs relating to reputation, female chastity and familial loyalty - but the effect is strongest in groups for whom honour is a culturally important theme, such as Latino men (Ijzerman \& Cohen, 2011). Posture can affect feelings of power across cultures, but the precise type of posture is culturally specific: an expansive feet-on-desk pose produces greater power activation in Americans, but inhibits power activation in East Asians, for whom it violates cultural norms of humility and restraint (Park, Streamer, Huang, \& Galinsky, 2013). Cultural and physiological influences on the mind therefore need not be considered opposing propositions; indeed, the cultural constitution of bodily experience may be a particularly effective mechanism by which a society's meanings are internalised by its citizens. Cultures map their prevailing values onto particular bodily states, such that adopting these poses makes their connected 
values psychologically salient. This dynamic circle of culture-body-mind influence ensures that cultural meanings are embedded within all levels of society, soma and psyche.

Thus, phenomenological philosophy and recent empirical research converge in pointing towards the mutual constitution of psychosocial and somatic experience. The notion that knowledge draws on embodied material remains compatible with the principle that representations are shared across communities: while some aspects of bodily experience are idiosyncratic to an individual's physiology, others are common to all members of a society, whether as a result of universal evolutionary inheritance (such as expressing grief by crying) or socialisation into culturally-constituted bodily meanings (such as expressing grief by wearing black). A comprehensive aetiology of social representations should therefore consider whether representations are shaped by the derivatives of phenomenological bodily experience, as well as social communication.

\section{HOW DOES THE BODY FEATURE IN EXISTING SRT LITERATURE?}

Although the role of bodily experience in the development of social representations has received little explicit theorisation, the body does frequently surface as a focus of concern in the empirical data SRT research has produced. Before outlining the key findings of this data, it is necessary to recall a distinction Husserl $(1913 / 2012)$ drew between the body-as-subject (Leib) and the body-as-object (Körper). Bodies are both physical structures and lived experiences; something we are and something we have (Crossley, 2001b; Varela, Thompson, \& Rosch, 1991). Thus far, SRT has afforded more attention to how we think about the body than how we think with the body. However, this literature remains interesting since the two facets are not independent: exploring social representations of the body can often be a particularly direct way of enlightening how first-person bodily experience interacts with social knowledge.

The most explicit elucidation of what the body offers for SRT is found within the writings of Denise Jodelet $(1984,1993)$. Jodelet (1984) contends that "the body appears as a privileged subject for research on social representations, in that it enables us to rediscover the social deep within the individual" (p. 212). Jodelet's (1984, 1993) research shows that the social dimensions of gender, class and generation stamp themselves on understandings of the body: in her studies, female associations with the word 'body' yielded a body that was dissected into different anatomical elements whereas men approached the body as a functional whole; upper class but not middle or lower class participants believed that inferences could be made from physical characteristics to psychological, moral and social traits; and the comparison of research undertaken in 1963 and 1975 revealed an historical change in French representations of the body, with a shift away from morbidity to more pleasurable states. Jodelet (1984) argues that the body is 'special' for 
SRT because of its dual character: it is simultaneously private and public, an object of both immediate sensory experience and meanings imposed by social sources. People's endeavours to represent their bodies must negotiate this interconnection between the subjective and the social. As such, representations of the body are a prime site at which the integration of social relations and private experience - a theoretical prerogative of SRT - can be observed (Wagner \& Hayes, 2005).

The most extensive elaboration of these processes has emanated from research on social representations of health and illness, which has traditionally formed a major empirical arm of SRT. Though these studies rarely make explicit reference to theories of embodiment, their cumulative implication has been that people's understandings of bodily processes express their surrounding social conditions. In this tradition, Herzlich's (1973) interviews with residents of Paris are paradigmatic. Herzlich (1973) reports that while her respondents saw health as a natural, harmonious state that required no explanation, illness was experienced as aberrant and jarring, which spurred a search for its causality. People largely assigned blame for illness to the 'unnatural' qualities of urban living, whose noises, foods and air were seen as 'toxic' to bodily equilibrium. These attributional patterns have been interpreted as responses to historically auspicious societal changes, as the widespread depopulation of the countryside would at the time have been fresh in French collective memory (Farr, 1993). A conceptualisation of illness in terms of assault from specified external agents is mirrored in British research by Blaxter (1997) and Pill and Stott (1982), which suggests that the attribution of illness to external sources functions as symbolic protest against harsh financial, occupational or residential conditions. Understandings of bodily function and dysfunction can thus absorb pertinent social concerns.

The saturation of bodily experience with social concerns implies that representations of health and illness will deviate systematically across cultures. SRT research has indeed shown that biomedically identical somatic symptoms elicit divergent cultural meanings, which affect how the symptoms are experienced and managed (Campbell, 2003; Joffe \& Bettega, 2003; Wagner, Duveen, Verma, \& Themel, 2000). The cultural contingency of health experience is neatly captured by Jovchelovitch and Gervais (1999), who show that individuals whose identity traverses two cultures (in this case, British-born persons of Chinese descent) absorb this duality into their representations of health and illness, which combine traditional (Eastern) and biomedical (Western) concepts and practices. Health and illness are therefore not purely physical phenomena: their experience is mediated by a network of meanings that cultures have imposed on somatic states.

This cultural influence on corporeal experience extends beyond issues of pathology. The most routine and everyday of bodily activities, such as walking, eating, sitting and clothing, are guided by cultural dictates about what is appropriate, desirable and necessary in particular contexts (Bourdieu, 1992; Mauss, 1936). SRT research has shown that these cultural conventions about bodily comportment are not arbitrary, but often function to reproduce social meanings and values. For example, Joffe and Staerklé (2007) elucidate how the cultural ethos of self-control is 
enacted in prescriptions to regulate bodily desires regarding sexuality, food and substance use. Restraint in these domains signals discipline and self-mastery, traits which are valorised in developed Western societies. In contrast, yielding to sensory indulgence is represented as a moral failing and serves as a basis on which traditionally stigmatised outgroups - including those who are overweight, sexually atypical or struggling with substance addiction - are derogated.

The field of intergroup relations is indeed a rich source of examples illustrating how social representations can be inscribed upon bodies. Howarth (2006) invokes the classical definition of 'stigma' as physical blemish (Goffman, 1963) to argue that stigma is literally incarnated by imbuing certain types of bodies with unfavourable associations. Research shows that representations of these stigmatised outgroups are often emotionally underscored by an affective response of disgust or repulsion. For example, Joffe (1999) demonstrates that the marginalisation of certain outgroups is premised on their representation as unclean or impure. SRT work on intergroup relations indicates that these disgust-responses tend to coincide with efforts to forge both symbolic and material distance - a fundamentally corporeal dimension - from derogated outgroups. An archetypal example is Jodelet's (1991) seminal study of representations of mental illness in the distinctive context of Ainay-le-Château, a French community where 'asylum' patients were housed within local homes. Jodelet (1991) observed that the host families implemented subtle practices that served to minimise physical contact with the patients with whom they shared a roof, exemplified in the widespread practice of separating the lodgers' laundry, cutlery and crockery from their own. The materialisation of intergroup divisions in differential levels of physical contact with members of other groups shows how bodily activity can perpetuate informal embargos on intergroup dialogue.

Thus, despite the relative paucity of formal theorisation of embodiment within SRT, the body is implicitly present in much of the empirical material that SRT has amassed. This material suggests that social representations often incorporate repertoires of evaluating and managing bodily states, thereby allowing abstract cultural meanings to acquire a material reality. SRT research shows that the social world acts on the body, guiding experience of one's own body, others' bodies, and abstract conceptualisations of body parts or states. However, SRT has yet to fully incorporate the reverse direction of the body-society relationship: that is, how bodily experience can constitute social psychological processes. The remainder of this paper considers what could be gained if SRT broadened its conception of bodily experience to regard it as an imput, rather than merely an output, of social representations.

HOW CAN EMBODIMENT CONCEPTS ENRICH SOCIAL REPRESENTATIONS THEORY AND RESEARCH?

There are already many points of overlap and synergy between SRT and embodiment research. As such, many of the opportunities that embodiment offers 
for SRT do not involve challenging core theoretical precepts, but rather reinforcing their validity and broadening the framework through which they are conceived and studied. The intent is to make the study of representation more comprehensive by considering how embodiment can underpin many of the social and psychological processes SRT documents.

First, installing the embodied, environmentally-embedded subject as psychology's appropriate focus affirms SRT's commitment to the intrinsically social nature of meaning. SRT's relative neglect of the body heretofore may partly ensue from its historical roots as a counterpoint to individualistic theories of social cognition (Farr, 1996; Moscovici, 1972). In this rhetorical context, focusing on external societal influences on thought may have taken priority over studying processes internal to individual physiology. However, body and environment are synergistic rather than opposing frameworks: situated approaches to embodiment maintain that acknowledging the body necessarily requires acknowledging the environment in which it is grounded (Barsalou, 2008; Gibson, 1979). As decades of anthropological research have shown (Durkheim, 1915; Mauss, 1936), the embodied experience is profoundly social: all social exchanges occur via sensorimotor processes and bodies are objects of multiform social meanings, from cultural definitions of attractiveness to expressions of social identity and interpersonal relations (Radley, 2000; Radley \& Billig, 1996). Incorporating embodiment concepts therefore corroborates rather than contradicts SRT's conviction in the social foundations of knowledge, and can lend additional heft to SRT's efforts to 're-socialise' social psychology (Moscovici, 1972).

Alongside emphasising the social, embodiment may also help SRT resuscitate the subject. Theoretically, SRT is committed to recognising individual subjectivity; indeed the origins of the term 'social representation' lie in Moscovici's (1961/2008) objection to the homogeneity implied by Durkheimian 'collective representations'. Nevertheless, SRT is often accused of advocating a form of social determinism or uniformity of opinion (e.g. Jahoda, 1988; Potter \& Litton, 1985). This reflects a misreading of SRT literature, which frequently refers to the dynamic, changeable nature of representations, and stipulates that common points of reference do not necessitate consensual agreement (Bauer \& Gaskell, 1999; Howarth, 2006; Rose et al., 1995). However, this misunderstanding may arise from the fact that in practice, SRT's empirical research tends to focus on identifying ideas that are shared across groups rather than directly studying individual variability (with some notable exceptions, e.g. Doise, Spini, \& Clémence, 1999). At first glance, Moscovici's statement that social representations "impose themselves upon us with an irresistible force" (Moscovici, 1984, p. 9) can be challenging to reconcile with individual innovation. Embodiment lends concrete mechanisms by which the dynamic between group consensuality and individual variability can be conceptualised. Gibson's (1979) theory of affordances stresses the intrinsically perspectival nature of meaning: perception is always rooted in a temporally-specific relation between a particular body and a 
particular environment. All individuals have completely unique embodied life-histories, and indeed unique bodies, which 'call out' different meanings (or affordances) from the same environmental features. At the same time, people who dwell in common cultural milieus have many common bodily experiences, and these "embodied schemas" (Ignatow, 2007, p. 128) may be an explanatory factor in social cleavages.

Considering social life in terms of body-environment interactions also admits individual and collective agency, since people and institutions can deliberately modulate their environment to control the affordances it provides (Gibson, 1979). They can similarly modify their bodies, whether by strengthening the musculoskeletal system, reflexively altering the body's symbolic and aesthetic attributes (Crossley, 2005), or purposely adopting postures that instil associated psychological experiences (Sartre, 1993; Merleau-Ponty, 1945/2002). Since a basic precept of SRT is that social representations can be reconstituted, challenged and resisted (Howarth, 2006), it may be empirically fruitful to remember that the body is one key - and under-researched - site at which this occurs (Foucault, 1979).

A related facet of SRT that embodiment concepts can enlighten is the role of emotional and/or unconscious mental content in representations (Joffe, 1996). A founding tenet of SRT was its opposition to rationalistic theories of cognition that privileged an idealised 'pure' logic. This view is now shared by most mainstream psychology, where the separation of emotion and reason is no longer seen as empirically tenable (Damasio, 2008; Zajonc \& Markus, 1984). Yet despite this vindication, it remains somewhat challenging to identify and characterise the affective content of social representations. This is largely due to the field's heavy reliance on verbal data from interviews and surveys, where emotional experience can only be inferred through participant introspection and/or researcher interpretation - both of which are valuable but fallible instruments. This becomes even more problematic when inferring the operation of unconscious motives, which by definition are inaccessible to verbal report. One route around this is to incorporate observation of bodies into the research variables. For instance, Jodelet's (1991) observation of how families separated their own possessions from those of their mentally ill lodgers points to unspoken motives whose potency was not fully evident in the interviews she conducted. Body-observations need not supplant techniques such as interviews, which continue to yield valuable insights into 'hot', emotion-infused thinking, but they do provide another source of evidence against which verbal data can be triangulated.

Considering the role bodies play in social life also orients the study of social representations more towards practice. Although Moscovici (1973, p. xiii) defines a social representation as a "system of values, ideas and practices", the latter element of this tripartite structure has been under-researched relative to the former two. This has provoked criticism of SRT from those who believe the essential function of social psychology is to predict behaviour (Fife-Schaw, 1997). SRT theorists counter by arguing that linear causal models over simplify and distort the complexity of social life, and that validly describing and interpreting 
social phenomena should take priority over narrow behavioural prediction (Joffe, 1997). However, while prediction need not be the goal, forging stronger links between social representations and practice would impel theoretical development by clarifying what is 'at stake' in a given representation. It would also strengthen the field's applied utility and relevance in non-academic contexts. For instance, in the context of demands for radical reduction of carbon output, recent research has applied SRT to explore how people's experience of urban environments shapes their aspirations for the future (Joffe \& Smith, 2016). The results show that the distinctive affordances that urban environments entail, related to such phenomena as stress, sociality and transport, are critical in understanding people's readiness to adapt their behaviour to the demands of a low-carbon society. Greater attention to how social representations interact with the behavioural repertoires that certain environments facilitate will help ensure the practical value of SRT research is acknowledged and exploited.

Finally, embodiment concepts may help enlighten the aetiology of social representations. In conceptualising the genesis of representations, SRT gives primacy to two processes: anchoring and objectification. Anchoring is essentially an act of classification that locates a new phenomenon relative to a culture's established array of categories, while objectification refers to the saturation of the new concept with tangible symbols, images and metaphors (Moscovici, 1961/2008). Anchoring a novel phenomenon in a familiar category furnishes a ready-made set of understandings by which the unfamiliar object can be conceptually grasped, while objectification assists cognition by reconstituting abstract ideas into the concrete material favoured by ordinary thinking (Wagner, 2007). Research confirms that the emergence of a novel phenomenon galvanises processes of communication wherein members of a society gradually convene on common anchors and objectifications (Wagner, Kronberger, \& Seifert, 2002). However, beyond the premise that the 'unknown' is made meaningful by linking it to the 'known', SRT has remained vague on the question of why particular categories and symbols are selected over others to foreground fledgling representations. One solution might be that certain symbols have greater bodily resonance for particular communities. Notably, embodiment theorists' conceptualisation of the mechanism by which embodiment priming effects develop - 'scaffolding' - bears striking similarity to the SRT concept of anchoring:

\footnotetext{
Features of abstract or less understood concepts are mapped onto existing and well-understood concepts, such that the structure of the developmentally earlier, primary concept is retained in the newly constructed concept. This structure imbues the newer concept with meaning. When an abstract concept is scaffolded onto a foundational concept, these concepts become associated, much in the same way semantically related concepts are naturally associated in the mind. (Williams, Huang, \& Bargh, 2009, p. 1257)
}

In the embodiment literature, scaffolding suggests that humans use basic dimensions of their sensorimotor experience of the physical world, such as temperature, 
distance and time, to develop higher-order concepts. Lakoff and Johnson's (1980) seminal text on metaphor is replete with examples of the reconstitution of abstract concepts into physical properties - for example, 'love is a journey' or 'good is up'. More abstract, conceptual information is comprehended by mapping it onto embodied knowledge, which both facilitates a greater breadth of conception and grounds thinking in the experiential physical environment (Gibbs, 2005; Williams et al., 2009). In SRT, anchoring and objectification are posited to root an abstract concept in something that is intellectually familiar, but it is notable that in many cases, this also amounts to rendering the abstract concept closer to bodily experience - that is, by objectifying it as something visible or tangible that commands an established repertoire of affective and motor responses (Wagner \& Hayes, 2005). For example, genetic engineering is objectified in images of 'Dolly the sheep' (Bauer \& Gaskell, 1999) and syringes defiling healthy tomatoes (Wagner \& Kronberger, 2001), while climate change is visualised in terms of polar bears stranded on melting ice (Smith \& Joffe, 2009). When confronted with an abstract phenomenon, societies can make it intelligible by reconstituting it into objects or concepts to which their members' sensorimotor repertoires allow either actual or imaginary access.

It should be noted that the scaffolding concept has a long history in developmental psychology, where it is associated with sociocultural theories of development (Vygotsky, 1978; Wood, Bruner, \& Ross, 1976). A pre-verbal infant's engagement with the world is exclusively embodied (Daum, Sommerville, \& Prinz, 2009), and sociocultural theorists hold that abstract skill acquisition occurs in social interaction, when more experienced individuals support the child in extending their cognitive and linguistic capacities. This social, interactional dimension of scaffolding is under-emphasised in embodied cognition researchers' use of the concept (Niedenthal \& Alibali, 2009). Nevertheless, there is no reason why cognitive and social conceptions of scaffolding cannot be usefully amalgamated in considering wherefrom social representations 'get' their content. That is, many anchoring/objectification projects could be conceptualised as a way of reconstituting the abstract concept in more embodied or experiential terms, and this task is achieved through interaction with others who expand one's physical and cognitive potentialities.

\section{AN EMPIRICAL EXAMPLE: SOCIAL REPRESENTATIONS OF NEUROSCIENCE}

An example of how embodiment concepts can enlighten otherwise puzzling data is a recent study undertaken to investigate social representations of neuroscience (O'Connor \& Joffe, 2014, 2015). SRT maintains a strong tradition of researching public engagement with science, which in contemporary society is the dominant authority on the body. Research on social representations of scientific topics has often assumed that social sources such as the mass media are the primary, or even 
sole, source of information about scientific issues (Wagner et al., 2002). However, when the scientific issue in question addresses human biology, social sources lose their status as exclusive carriers of information: by virtue of possessing a body, the individual also has a direct, personal route of access to the phenomenon. The O'Connor and Joffe (2014) study suggests that this subjective experience can shape the pathways along which science assimilates into public consciousness.

The scientific and public profile of neuroscience has grown sharply in recent years, with neuroscientific concepts frequently invoked in popular media and public policy (O'Connor et al., 2012; Rose \& Abi-Rached, 2013). The prominence of neuroscience in popular culture has led some commentators to speculate that we are entering a 'neuro-society' in which common-sense notions of personhood and behaviour are being radically reconfigured in neuroscientific terms (Abi-Rached, 2008; Lynch, 2009). However, empirical investigation of neuroscience's resonance in the day-to-day lives of ordinary people has failed to vindicate these propositions. A recent study interviewed a socially diverse sample of 48 London residents to ascertain the associations they held with the concept of 'brain research' (O'Connor \& Joffe, 2014). The analysis revealed that despite neuroscience's visibility in today's public sphere, for most of these participants brain research was a distant, alien and somewhat threatening domain. Some participants indicated that in their ordinary course of life they would actively resist thinking about the operations of their brain, because this would incite a sense of cognitive or existential discomfort. Accustomed to the brain's usual invisibility, people were apprehensive about the prospect of technologies that could expose or manipulate its operations, describing this as a violation or intrusion. Thus, the people in this sample were disengaged from contemporary neuroscience because they construed the knowledge it produced as either irrelevant or unsettling. Similar results are reported by Pickersgill, Cunningham-Burley, and Martin (2011) and Choudhury, McKinney, and Merten (2012).

The finding of widespread detachment from contemporary brain research is surprising, given its stark contrast with research documenting neuroscience's regular appearance in the popular media - indeed, in the very newspapers that these participants reported consuming (O'Connor et al., 2012). Recourse to the embodiment literature furnishes concepts that may help to resolve this puzzle. An obliviousness to physiological processes is consistent with the writings of numerous phenomenological philosophers, who suggest that the key marker of a healthy body is its absence from conscious awareness (Canguilhem, 1966/1991; Sartre, 1943/2000). This is not to say that the body is unimportant for thinking, but rather that the functional holism of body and self (Leib) is such that we rarely consciously reflect on our body as an objective entity (Körper). Csordas (1990) states that "a fully phenomenological account would recognize that while we are capable of becoming objects to ourselves, in daily life this seldom occurs." (p. 6). This idea has been particularly extensively developed by Drew Leder (1990), who argues that for the body to effectively fulfil its role in perception and action, it 
must recede or 'disappear' from consciousness so that attention can be fully directed into the external world. Leder (1990) stipulates that bodily disappearance is particularly pertinent in relation to one's internal organs, whose only means of observation are science, its instruments and its anatomical models. He suggests that when people do encounter scientific images of their own internal organs, the experience is marked by a 'strangeness' and non-recognition, due to the image's phenomenological non-coincidence with the body-as-lived. This echoes the observations of Jean-Paul Sartre (1943/2000), who describes the intense struggle entailed in attempts to marry the subjective experience of the lived body with intellectual knowledge of biological concepts and imagery. These philosophers suggest that encounters with the science of human biology are somewhat uncomfortable, as they contradict the phenomenological system's preference to remain unconscious of one's bodily processes. Their insights can contextualise and explain the disengagement and discomfort with neuroscience identified in the above research.

Bodily disappearance is not inexorable, however. In the O'Connor and Joffe (2014) study, participants consistently asserted that the only context in which they would be motivated to engage with brain science would be if they developed a neurological disorder: direct experience of their own brain 'going wrong' would be necessary to prompt them to directly reflect on the organ sitting inside their head. Research indeed finds greatly enhanced levels of engagement with neuroscience amongst clinical populations (Buchman, Borgelt, Whiteley, \& Illes, 2013; Singh, 2013). This accords with Leder's (1990) contention that the primary means by which inattention to the body can be ruptured is the experience of pain, discomfort or disease: the body seizes attention at times of dysfunction. The ordinary disappearance of the body is therein replaced by the body's 'dys-appearance', which Leder (1990) defines as the surfacing of the body as a thematic focus, but in a 'dys' state. For participants in the O'Connor and Joffe (2014) study, this natural bias of attention towards the pathological set the tone for conceptualising the more general category of brain research, which was widely assumed to be a medical field whose primary function was to cure neurological illness. The relevance of this embodiment effect may extend beyond neuroscience to account for a more general medicalisation of science: previous survey research suggests that medicine is paradigmatic in public conceptions of 'what science is' (Bauer, 1998; Durant, Evans, \& Thomas, 1992). Social representations of science may be shaped by a phenomenological tendency that disproportionately weights conceptions of the body towards dysfunction and pathology.

Thus, the O'Connor and Joffe (2014) data revealed a distancing from neuroscience generally, as well as a pathologisation of the brain and corresponding medicalisation of brain research. These findings could not be explained by solely looking outward into the discourses of the media, wherein neuroscience occupied a prominent position and where brain enhancement took priority over brain pathology (O'Connor et al., 2012). Absorbing insights from phenomenology 
threw light on the data by proposing that the bodily disappearance that characterises human embodiment impedes the wider dissemination of neuroscientific ideas. Though neuroscience findings can circulate within cultural artefacts such as the media, they may experience difficulty penetrating lay consciousness if their decoding of the brain clashes with - and may disrupt the smooth functioning of - the embodied experience. The O'Connor and Joffe (2014) study thus demonstrates how facets of data that would thwart a standard SRT analysis can be resolved by turning to principles derived from the embodiment literature. It suggests that embodied experience can shape the extent to which people engage with certain topics, the conditions under which they do so, and the conceptual and affective content of the ensuing representations.

\section{HOW CAN SRT CONCEPTS ENRICH EMBODIMENT THEORY AND RESEARCH?}

The primary purpose of this article is to highlight the opportunities that embodiment offers for SRT. However, it is important to note that the benefits would likely be reciprocal. In particular, while early phenomenological and anthropological frameworks characterised the body as inherently social, the social dimension of embodiment is marginal in current embodied cognition research (Ignatow, 2007). In common with much experimental psychological research, embodied cognition studies tend to adopt a methodological individualism that studies atomised individuals in artificial laboratory contexts. This is despite the fact that social factors are integral in the wider conceptual context of this research. For instance, many embodiment priming experiments take as their premise metaphors that are common to a society, but never query how those metaphors arose or are sustained through social communication. The clear implication is that socio-cultural material influences bodily experience, yet the mechanisms through which this occurs are not theorised. In contrast, SRT is specifically designed to explore how ideas are generated in social communication and consolidated in bodies, behaviour and environment. Many aspects of SRT would prove valuable in illuminating the social foundations and consequences of embodiment effects, such as its incorporation of cultural artefacts as research material (Lahlou, 1996) and encouragement of cross-cultural research (e.g. Joffe, Rossetto, Solberg, \& O'Connor, 2013). As such, incorporating SRT principles into the embodiment sphere can help 'close the circle' in theorising the reciprocal links between embodied experience, social interaction and psychological content.

Undoubtedly, integrating the two theoretical traditions will not be entirely smooth, as many conceptual and methodological tensions remain. Embodied cognition's reliance on experimental methods may controvert SRT theorists' commitment to more naturalistic techniques. A further conceptual difference is that some (although not all) proponents of embodiment strongly advocate an anti-representationalist stance, which SRT contradicts by its very name. Both 
Merleau-Ponty (1945/2002) and Gibson (1979) suggest that people act in direct response to one's sense of a situation, without any mediating mental representation. This is echoed by contemporary theorists who argue that positing the existence of internal propositional representations is unnecessary to explain perception, cognition or action (Chemero, 2009; Dreyfus, 2002; Varela et al., 1991; Spackman \& Yanchar, 2014). However, this stance is arguably less sustainable when the perception, cognition or action is social in nature. Gibson (1979) acknowledges that many important environmental affordances are other people and states that while these interactions are complex, they are nevertheless governed by laws covered by his model of ecological perception; yet he evades specifying the nature of those laws (Costall, 1995). It is difficult to understand how communication and cooperation could occur without some shared understanding of the situation at hand. Decades of social psychological research show that the meaning of another's behaviour is not intrinsic, but requires considerable mediating judgement and interpretation. Social representations are one source posited to guide this interpretation. It is worth noting they are not exactly the 'internal' representations to which anti-representationalists object: social representations reside across rather than within minds, and are consolidated in cultural artefacts and social communication rather than decontextualized individual thought (Jovchelovitch, 2007). SRT agrees that cognition arises in the direct interaction of person and environment, but sees the environment in question as socially constructed rather than physically given.

The inevitable tensions between SRT and embodiment approaches should not inhibit dialogue. Fruitful collaboration does not require total acceptance of all precepts of the partner theory. For instance, SRT need not adopt the a priori position that all meaning is intrinsically embodied or that embodiment is the most critical dimension to consider. It is sufficient to start from the premise that some meaning is undoubtedly embodied in important ways, and that exploring this facet of human experience may yield theoretical and empirical advances. Neither must embodiment theorists necessarily accept the social constructionist tenets of SRT: its empirical accounts of social communication and understanding remain comprehensible without this epistemological foundation. An à la carte approach, whereby each field selectively engages with elements of the other that they find useful, is an acceptable starting-point for a new dialogical enterprise.

\section{DIRECTIONS FOR FUTURE RESEARCH}

Incorporating consideration of embodiment into SRT research requires an expansion of SRT's typical methodological toolkit. With some notable exceptions (e.g. Duveen \& Lloyd, 1993; Jovchelovitch, Priego-Hernández \& Glăveanu, 2013; Smith \& Joffe, 2009), SRT research tends to rely on verbal empirical material generated by interviews, surveys or textual analysis. This may narrow 
the scope of its insight into embodiment, as evidence of bodily experience can only be gleaned indirectly through inference from respondents' verbal articulations, rather than primary data on somatic experience. Reliance on verbal data collected at a single time and place also gives rise to a relatively static operationalisation of embodied experience, which assumes that the embodiment phenomena that surfaced within that research context represent stable phenomenological propensities. This overlooks the premise that the body makes itself felt primarily through its movement through the world. Gillespie and Zittoun (2013) argue that meaning is made in motion, as bodies and minds move between different physical and social contexts. Incorporating direct observation of moving, acting bodies should be a priority for future research aiming to unpick the role of the body in the development of social knowledge. A useful precedent is Jodelet's (1991) report of the physical separations of activity and possessions that were implemented by families who housed mentally ill lodgers. Further methodological opportunities could be culled from the innovative techniques employed in the embodied cognition tradition. For instance, would inducing particular bodily states in participants, by modulating environmental conditions or semantic prompts, produce systematically different representational content? Greater attention to such environmental contingencies would orient SRT towards the more dynamic, on-line processes of social meaning-making.

However, it should be stated that while some methodological innovation may be helpful in opening up new lines of inquiry, novel methodological paradigms are not an absolutely necessary prerequisite for furthering the study of the body in social representation. Margaret Lock's (2001) anthropological work on 'local biologies' is an excellent example of how, with the right analytic lens, traditional survey and interview designs can be exploited to furnish rich insight into embodied experience - in Lock's (2001) case, to demonstrate that biological phenomena presumed to be universal, such as menopausal symptoms, are experienced in fundamentally different ways across cultural contexts. In pursuing a robust study of embodied representation, the demands are conceptual as much as methodological. Even with conventional interview data, conceptual sensitivity to the import of embodiment can be built into the analysis process by explicitly attending to the latent sensory dimensions of the language (e.g. verbs like 'see' or 'feel') or metaphors used (e.g. whether a particular objectification is visual, haptic or kinetic). Conceptualising this content as embodied (as well as social, emotional and/or intellectual) adds an extra level to the theorisation of knowledge and may help resolve some issues that have thus far remained elusive. For example, in the development of a new social representation, the factors that influence a community's selection of certain anchors and objectifications over others remain opaque. It is worth considering whether bodily imperatives might constitute a motivational force in the aetiology of representation, with people gravitating towards meanings that cohere with their bodily predilections (e.g. as in O'Connor and Joffe [2014], a tendency to represent biological processes as a source of pathology rather than health). 
The study of the body's role in constituting psychological and social life has recently been revitalised by emerging research in the field of embodied cognition. SRT dovetails with this literature in several conceptual and empirical preoccupations - for example, in the premise that affect and intergroup relations are formative influences on psychological life, and a concern with collapsing the duality of person/environment. However, as yet SRT's engagement with concepts of embodiment has been minimal. Although in principle SRT acknowledges that navigating the world is a material as well as social enterprise, in practice its investigation of the development of social representations has tended to look externally into the social world, rather than internally into the embodied experience. Expanding SRT's field of analysis, such that it illuminates the interplay between embodied phenomenology and social communication in the development of common-sense knowledge, promises productive directions for empirical and theoretical advancement.

\section{Cliodhna O'Connor \\ Department of Psychology, Maynooth University, Maynooth, Co. Kildare, Ireland \\ Cliodhna.OConnor@nuim.ie}

Acknowledgements. Some of the work reported in this paper was supported by a Uses and Abuses of Biology grant awarded by The Faraday Institute at St. Edmund's College, Cambridge. The author thanks Prof. Helene Joffe for her comments on an earlier draft of this manuscript.

\section{REFERENCES}

Abi-Rached, J. M. (2008). The implications of the new brain sciences. EMBO Reports, 9, 1158-1162.

Barsalou, L. W. (2008). Grounded cognition. Annual Review of Psychology, 59, 617-645.

Bauer, M. W. (1998). The medicalization of science news - from the "rocket-scalpel" to the "gene-meteorite" complex. Social Science Information, 37, 731-751.

Bauer, M. W., \& Gaskell, G. (1999). Towards a paradigm for research on social representations. Fournal for the Theory of Social Behaviour, 29, 163-186.

Blaxter, M. (1997). Whose fault is it? People's own conceptions of the reasons for health inequalities. Social Science E Medicine, 44, 747-756.

Bourdieu, P. (1992). Language and symbolic power. Cambridge: Polity Press.

Buchman, D. Z., Borgelt, E. L., Whiteley, L., \& Illes, J. (2013). Neurobiological narratives: Experiences of mood disorder through the lens of neuroimaging. Sociology of Health $\mathbb{E}^{\circ}$ Illness, 35, 66-81. 
Campbell, C. (2003). Letting them die: Why HIV/AIDS prevention programmes fail. Oxford: James Currey.

Canguilhem, G. (1966/1991). The normal and the pathological (C. R. Fawcett \& R. S. Cohen, Trans.). New York: Zone Books.

Chemero, A. (2009). Radical embodied cognitive science. Cambridge, MA: MIT Press.

Choudhury, S., McKinney, K. A., \& Merten, M. (2012). Rebelling against the brain: Public engagement with the 'neurological adolescent'. Social Science \& Medicine, 74, 565-573.

Clark, A., \& Chalmers, D. J. (1998). The extended mind. Analysis, 58, 7-19.

Cohen, D., \& Leung, A. K. Y. (2009). The hard embodiment of culture. European fournal of Social Psychology, 39, 1278-1289.

Costall, A. (1995). Socializing affordances. Theory \& Psychology, 5(4), 467-481.

Crossley, N. (1995). Merleau-Ponty, the elusive body and carnal sociology. Body EO Society, 1, 43-63.

Crossley, N. (2001a). Merleau-Ponty. In B. Turner \& A. S. Elliott (Eds.), Profiles in contemporary social theory (pp. 30-42). London: Sage.

Crossley, N. (2001b). The social body: Habit, identity and desire. London: Sage.

Crossley, N. (2005). Mapping reflexive body techniques: On body modification and maintenance. Body \& Society, 11, 1-35.

Csordas, T. J. (1990). Embodiment as a paradigm for anthropology. Ethos, 18, 5-47.

Damasio, A. (2008). Descartes' error: Emotion, reason and the human brain. London: Random House.

Danziger, K. (1990). Constructing the subject. Cambridge: Cambridge University Press.

Daum, M. M., Sommerville, J. A., \& Prinz, W. (2009). Becoming a social agent: Developmental foundations of an embodied social psychology. European fournal of Social Psychology, 39, 1196-1206.

Descartes, R. (1637/1980). Discourse on the method (D. A. Cress, trans.). Indianapolis, IN: Hackett.

Doise, W., Spini, D., \& Clémence, A. (1999). Human rights studied as social representations in a cross-national context. European Fournal of Social Psychology, 29, 1-29.

Dreyfus, H. L. (2002). Intelligence without representation-Merleau-Ponty's critique of mental representation the relevance of phenomenology to scientific explanation. Phenomenology and the Cognitive Sciences, 1, 367-383.

Durant, J., Evans, G., \& Thomas, G. (1992). Public understanding of science in Britain: The role of medicine in the popular representation of science. Public Understanding of Science, 1, 161-182.

Durkheim, E. (1915). The elementary forms of religious life. New York, NY: Free Press.

Duveen, G., \& Lloyd, B. (1993). An ethnographic approach to social representations. In G. M. Breakwell, \& D. V. Canter (Eds), Empirical approaches to social representations (pp. 90-109). New York: Clarendon Press.

Farr, R. M. (1993). Common sense, science and social representations. Public Understanding of Science, 2, 189-204.

Farr, R. M. (1996). The roots of modern social psychology, 1872-1954. Malden: Blackwell Publishing.

Fife-Schaw, C. (1997). Commentary on Joffe (1996) AIDS research and prevention: A social representational approach. British Fournal of Medical Psychology, 70, 65-73.

Fiske, S. T., Guddy, A. J. C., \& Glick, P. (2007). Universal dimensions of social cognition: Warmth and competence. Trends in Cognitive Sciences, 11, 77-83.

Foucault, M. (1979). The history of sexuality (R. Hurley, trans.). London: Allen Lane.

Gibbs, R. W. (2005). Embodiment in metaphorical imagination. In D. Pecher \& R. A. Zwaan (Eds.), Grounding cognition: The role of perception and action in memory, language and thinking (pp. 65-92). New York: Cambridge University Press.

Gibson, J. J. (1979). The ecological approach to visual perception. Boston: Houghton Mifflin. 
Gillespie, A., \& Zittoun, T. (2013). Meaning making in motion: Bodies and minds moving through institutional and semiotic structures. Culture $\mathcal{E}$ Psychology, 19, 518-532.

Goffman, E. (1963). Stigma: Notes on the management of spoiled identity. Englewood Cliffs, NJ: Prentice-Hall.

Goldman, A., \& de Vignemont, F. (2009). Is social cognition embodied? Trends in Cognitive Sciences, 13, 154-159.

Herzlich, C. (1973). Health and illness: A social psychological analysis. London: Academic Press.

Hirose, N. (2002). An ecological approach to embodiment and cognition. Cognitive Systems Research, 3(3), 289-299.

Howarth, C. (2006). Race as stigma: Positioning the stigmatized as agents, not objects. Fournal of Community \& Applied Social Psychology, 16, 442-451.

Husserl, E. (1913/2012). Ideas: General Introduction to Pure Phenomenology (W. R. B. Gibson, Trans). New York: Routledge.

Ignatow, G. (2007). Theories of embodied knowledge: New directions for cultural and cognitive sociology? Fournal for the Theory of Social Behaviour, 37, 115-135.

Ijzerman, H., \& Cohen, D. (2011). Grounding cultural syndromes: Body comportment and values in honor and dignity cultures. European Journal of Social Psychology, 41, 456-467.

Jahoda, G. (1988). Critical notes and reflections on 'social representations'. European fournal of Social Psychology, 18, 195-209.

James, W. (1912/2003). Essays in radical empiricism. Mineola, NY: Dover.

Jodelet, D. (1984). The representation of the body and its transformations. In R. M. Farr \& S. Moscovici (Eds.), Social representations (pp. 211-237). Cambridge: Cambridge University Press.

Jodelet, D. (1991). Madness and social representations: Living with the mad in one French community. Los Angeles, CA: University of California Press.

Jodelet, D. (1993). Indigenous psychologies and social representations of the body and self. In U. Kim \& J. W. Berry (Eds.), Indigenous psychologies: Research and experience in cultural context (pp. 177-191). London: Sage.

Joffe, H. (1996). The shock of the new: A psycho-dynamic extension of social representational theory. Fournal for the Theory of Social Behaviour, 26, 197-219.

Joffe, H. (1997). Juxtaposing positivist and non-positivist approaches to social scientific AIDS research: Reply to Fife-Schaw's commentary. British Fournal of Medical Psychology, $70,75-83$.

Joffe, H. (1999). Risk and 'the other'. Cambridge: Cambridge University Press.

Joffe, H., \& Bettega, N. (2003). Social representations of AIDS among Zambian adolescents. Fournal of Health Psychology, 8, 616-631.

Joffe, H., \& Smith, N. (2016). City dweller aspirations for cities of the future: How do environmental and personal wellbeing feature? Cities, 8, 102-112.

Joffe, H., \& Staerklé, C. (2007). The centrality of the self-control ethos in Western aspersions regarding outgroups: A social representational approach to stereotype content. Culture \& Psychology, 13, 395-418.

Joffe, H., Rossetto, T., Solberg, C., \& O’Connor, C. (2013). Social representations of earthquakes: A study of people living in three highly seismic areas.Earthquake Spectra, 29, 367-397.

Johnson, M. (1987). The body in the mind: The bodily basis of meaning, imagination, and reason. Chicago: University of Chicago Press.

Jovchelovitch, S. (2007). Knowledge in context: Representations, community and culture. London: Routledge.

Jovchelovitch, S., \& Gervais, M.-C. (1999). Social representations of health and illness: The case of the Chinese community in England. Fournal of Community \& Applied Social Psychology, 9, 247-260. 
Jovchelovitch, S., Priego-Hernández, J., \& Glăveanu, V. P. (2013). Constructing public worlds: Culture and socio-economic context in the development of children's representations of the public sphere. Culture \& Psychology, 19, 323-347.

Lahlou, S. (1996). The propagation of social representations. Fournal for the Theory of Social Behaviour, 26, 157-175.

Lakoff, G., \& Johnson, M. (1980). Metaphors we live by. Chicago: University of Chicago Press. Leder, D. (1990). The absent body. Chicago: University of Chicago Press.

Lock, M. (2001). The tempering of medical anthropology: Troubling natural categories. Medical Anthropology Quarterly, 15, 478-492

Lupton, D. (1998). Going with the flow: Some central discourses in conceptualising and articulating the embodiment of emotional states. In S. Nettleton \& J. Watson (Eds.), The body in everyday life (pp. 82-99). London: Routledge.

Lynch, Z. (2009). The neuro revolution: How brain science is changing our world. New York: St. Martin's Press.

MacLachlan, M. (2004). Embodiment: Clinical, critical and cultural perspectives on health and illness. Maidenhead: Open University Press.

Marsh, K. L., Johnston, L., Richardson, M. J., \& Schmidt, R. C. (2009). Toward a radically embodied, embedded social psychology. European Fournal of Social Psychology, 39, 1217-1225.

Mauss, M. (1936). Les techniques du corps. Fournal de Psychologie, 32, 365-86.

Meier, B. P., \& Robinson, M. D. (2004). Why the sunny side is up: Associations between affect and vertical position. Psychological Science, 15, 243-247.

Meier, B. P., Schnall, S., Schwarz, N., \& Bargh, J. A. (2012). Embodiment in social psychology. Topics in Cognitive Science, 4, 705-716.

Merleau-Ponty, M. (1945/2002). Phenomenology of perception (C. Smith, Trans.). London: Routledge.

Moscovici, S. (1961/2008). Psychoanalysis: Its image and its public (D. Macey, Trans.). Cambridge: Polity Press.

Moscovici, S. (1972). Society and theory in social psychology. In J. Israel \& H. Tajfel (Eds.), The context of social psychology: A critical assessment (pp. 17-68). London: Academic Press.

Moscovici, S. (1973). Introduction. In C. Herzlich (Ed.), Health and illness: A social psychological analysis (pp. ix-xiv). London: Academic Press.

Moscovici, S. (1984). The phenomenon of social representations. In R. Farr \& S. Moscovici (Eds.), Social representations. (pp. 3-69). Cambridge: Cambridge University Press.

Niedenthal, P. M., \& Alibali, M. W. (2009). Conceptualizing scaffolding and goals for a full account of embodied cognition. European Fournal of Social Psychology, 39, 1268-1271.

Niedenthal, P. M., Barsalou, L. W., Winkielman, P., Krauth-Gruber, S., \& Ric, F. (2005). Embodiment in attitudes, social perception, and emotion. Personality and Social Psychology Review, 9, 184-211.

O'Connor, C., \& Joffe, H. (2014). Social representations of brain research: Exploring public (dis)engagement with contemporary neuroscience. Science Communication, 36, 617-645.

O'Connor, C., \& Joffe, H. (2015) How the public engages with brain optimization: The media-mind relationship. Science, Technology \& Human Values, 40, 712-743.

O’Connor, G., Rees, G., \& Joffe, H. (2012). Neuroscience in the public sphere. Neuron, 74, 220-226.

Park, L. E., Streamer, L., Huang, L., \& Galinsky, A. D. (2013). Stand tall, but don't put your feet up: Universal and culturally-specific effects of expansive postures on power. Fournal of Experimental Social Psychology, 49, 965-971.

Pecher, D., \& Zwaan, R. A. (2005). Introduction. In D. Pecher \& R. A. Zwaan (Eds.), Grounding cognition: The role of perception and action in memory, language and thinking (pp. 1-7). New York: Cambridge University Press. 
Pickersgill, M., Cunningham-Burley, S., \& Martin, P. (2011). Constituting neurologic subjects: Neuroscience, subjectivity and the mundane significance of the brain. Subjectivity, 4, 346-365.

Pill, R., \& Stott, N. C. (1982). Concepts of illness causation and responsibility: some preliminary data from a sample of working class mothers. Social Science \& Medicine, 16, 43-52.

Potter, J., \& Litton, I. (1985). Some problems underlying the theory of social representations. British Fournal of Social Psychology, 24, 81-90.

Radley, A. (2000). Health psychology, embodiment and the question of vulnerability. Journal of Health Psychology, 5, 297-304.

Radley, A., \& Billig, M. (1996). Accounts of health and illness: Dilemmas and representations. Sociology of Health \& Illness, 18, 220-240.

Rose, D., Efraim, D., Gervais, M.-C., Joffe, H., Jovchelovitch, S., \& Morant, N. (1995). Questioning consensus in social representations theory. Papers on Social Representations, 4, $150-176$.

Rose, N. (2013). The human sciences in a biological age. Theory, Culture \&o Society, 30, 3-34.

Rose, N., \& Abi-Rached, J. M. (2013). Neuro: The new brain sciences and the management of the mind. Princeton, NJ: Princeton University Press.

Ryle, G. (1949). The concept of mind. London: Hutchinson.

Sartre, J.-P. (1943/2000). Being and nothingness (H. E. Barnes, Trans.). London: Routledge.

Sartre, J.-P. (1993) The Emotions: Sketch for a Theory. New York: Citadel

Schubert, T. W. (2004). The power in your hand: Gender differences in bodily feedback from making a fist. Personality and Social Psychology Bulletin, 30, 757-769.

Schubert, T. W., \& Semin, G. R. (2009). Embodiment as a unifying perspective for psychology. European Fournal of Social Psychology, 39, 1135-1141.

Searle, J. (1995). The construction of social reality. New York: The Free Press.

Singh, I. (2013). Brain talk: Power and negotiation in children's discourse about self, brain and behaviour. Sociology of Health E Illness, 35, 813-827.

Smith, N., \& Joffe, H. (2009). Climate change in the British press: The role of the visual. Journal of Risk Research, 12, 647-663.

Soussignan, R. (2002). Duchenne smile, emotional experience, and autonomic reactivity: A test of the facial feedback hypothesis. Emotion, 2, 52-74.

Spackman, J. S., \& Yanchar, S. C. (2014). Embodied cognition, representationalism, and mechanism: a review and analysis. Fournal for the Theory of Social Behaviour, 44, 46-79.

Varela, F. J., Thompson, E., \& Rosch, E. (1991).The embodied mind. Cambridge, MA: MIT Press.

Vygotsky, L. S. (1978). Interaction between learning and development. In M. Cole, V. John-Steiner, S. Scribner, \& E. Souberman (Eds.), Mind in society: The development of higher psychological processes (pp. 79-91). Cambridge, MA: Harvard University Press.

Wagner, W. (2007). Vernacular science knowledge: Its role in everyday life communication. Public Understanding of Science, 16, 7-22.

Wagner, W., \& Hayes, N. (2005). Everyday discourse and common sense: The theory of social representations. Basinsgstoke: Palgrave MacMillan.

Wagner, W., \& Kronberger, N. (2001). Killer tomatoes! Collective symbolic coping with biotechnology. In K. Deaux \& G. Philogène (Eds.), Representations of the social (pp. 147164). Oxford: Blackwell.

Wagner, W., Duveen, G., Verma, J., \& Themel, M. (2000). 'I have some faith and at the same time I don't believe' - cognitive polyphasia and cultural change in India. Fournal of Community \& Applied Social Psychology, 10, 301-314.

Wagner, W., Kronberger, N., \& Seifert, F. (2002). Collective symbolic coping with new technology: Knowledge, images and public discourse. British fournal of Social Psychology, 41, 323-343. 
Wells, G. L., \& Petty, R. E. (1980). The effects of over head movements on persuasion: Compatibility and incompatibility of responses. Basic and Applied Social Psychology, 1, 219-230.

Wilkowski, B. M., Meier, B. P., Robinson, M. D., Carter, M. S., \& Feltman, R. (2009). "Hot-headed" is more than an expression: The embodied representation of anger in terms of heat. Emotion, 9, 464 477.

Williams, L. E., Huang, J. Y., \& Bargh, J. A. (2009). The scaffolded mind: Higher mental processes are grounded in early experience of the physical world. European Fournal of Social Psychology, 39, 1257-1267.

Wilson, M. (2002). Six views of embodied cognition. Psychonomic Bulletin \& Review, 9, 625-636.

Wood, D., Bruner J., \& Ross, G. (1976). The role of tutoring in problem solving. Fournal of Child Psychology and Psychiatry, 17, 89-100.

Zajonc, R. B., \& Markus, H. (1984). Affect and cognition: The hard interface. In C. Izard, J. Kagan, \& R. B. Zajonc (Eds.), Emotions, cognition and behavior (pp. 73-102). Cambridge, England: Cambridge University Press.

Zhong, C.-B., \& Leonardelli, G. J. (2008). Cold and lonely: Does social exclusion literally feel cold? Psychological Science, 19, 838-842. 